\title{
Investigation of the influence of Br- and As-doped silica single-wall nanotubes: Hartree-Fock method
}

\author{
ABDEL-BASET H MEKKY, \\ ${ }^{1}$ Faculty of Science and Arts El-Mozneb, Qassim University, El-Mozneb 51931, Kingdom of Saudi Arabia \\ ${ }^{2}$ High Institute of Engineering and Technology, Buhaira, Egypt \\ univ.physics@yahoo.com
}

MS received 28 November 2017; accepted 9 February 2018; published online 7 December 2018

\begin{abstract}
Synthesis of silica single-wall nanotubes was reported based on single-membered ring (single unit cell) with the element As. These results are supported by performing the Hartree-Fock/6-311G method. The electronic structure, optical band gaps, hardness $(\eta)$ and softness $(S)$ are discussed. No difference in the computed bond length and angle of doped silica was found. Doping of $\mathrm{As}$ and $\mathrm{Br}$ atoms leads to a decrease in the energy gap of pure silica. This will make the silica doped with $\mathrm{Br}$ and As molecules not require more energy to be excited.
\end{abstract}

Keywords. Silica nanotubes; HF method; Gaussian model; electronic and structural properties; optical band gaps; hardness.

\section{Introduction}

Cluster-derived Si nanotubes are encouraging candidates for different parts of forthcoming nanodevices [1]. Si nanotubes' low dimensionality causes quantum effects which are often harnessed to regulate the electronic digital properties [2-7]. This begins the route for most probable uses together with electronic digital devices, for example, nano-scale transistors [8-15], high levels of sensitivity, chemical and natural detectors [16-21] and optoelectronic procedures [22-25]. A number of theoretical investigations have led to the properties of SiNWs as a function of crystallographic development direction, radial measurements, chemical substance doping and surface renovation [2-5,26-36]. Many computational approaches have been formulated to treat structures of many systems containing semi-empirical methods [35], DFT-based limited binding (DFTB) assessments [45,50], DFT theory approximations [4-7,32,35,36], other than many-body disconcertion principles inside the GW methodology [32]. These investigations show that the quantum size of SiNWs smaller than $4 \mathrm{~nm}$ prevail in the results. Even it can be expected that by reducing the size of NWs brought about two results together with an increase in the band gap of the material, occasionally, by moving from an indirect to a primary space [3-5,37]. Theoretical studies on silica nanotubes (SiNTs) have recently emerged focusing on single-walled SP2 SiNTs, which form silicon analogues of CNTs [38-40]. The system structure was considered to be chirality-based mostly with the change from metallic to semi-conducting with regard to the chiral vector orientation, which is similar to the reason behind their carbon equivalents [38,39]. Further, it has been shown that a little distorted composition of single-walled locations where in fact the
$\mathrm{Si}-\mathrm{Si}$ bonds have a relatively enhanced SP3 identity which is more steady compared to the pristine CNT-like composition [39,41-43]. In addition, determining the properties of SP2 SiNTs by using several hydrogenation techniques has been explored [43]. Apart from the SP2 model, prismane-like $[44,45]$ SiNTs made of stacked and covalently bonded square, pentagonal and hexagonal silicon bands have predicted to be metallic in nature. Until now, the nature of $\mathrm{Br}$ and As element impurities in SiNTs has not been premeditated by molecular modelling techniques. The objective of this work is to fill the lacuna in this direction. This report shows that it is possible to compute the structure, energy band gaps and mechanical properties of SiNTs plus some of its derivatives that doped with $\mathrm{Br}$ and As elements by using the Hartree-Fock (HF) method/6-311G level.

\section{Methodology}

Silica single-wall nanotube potential predicated for one-membered ring (one unit cell) and its own doping instances by $\mathrm{Br}$ and $\mathrm{As}$ has been illustrated using quantum computations predicated on the HF method at the 6-311G level. We have based our understanding on molecules, structures and hardness of the examined silica single-wall structure nanotubes predicated on the one-membered band (one product cell) and its own doping instances by $\mathrm{Br}$ and As. This was executed by using the Gaussian03/W software package [49] to completely optimize the varieties individually in the gasification stage.

Hardness $(\eta)$ of the fragment is given as [48]

$$
\eta=-1 / 2\left(E_{\mathrm{HOMO}}-E_{\mathrm{LUMO}}\right)
$$


$\mathrm{SiO}_{2}$

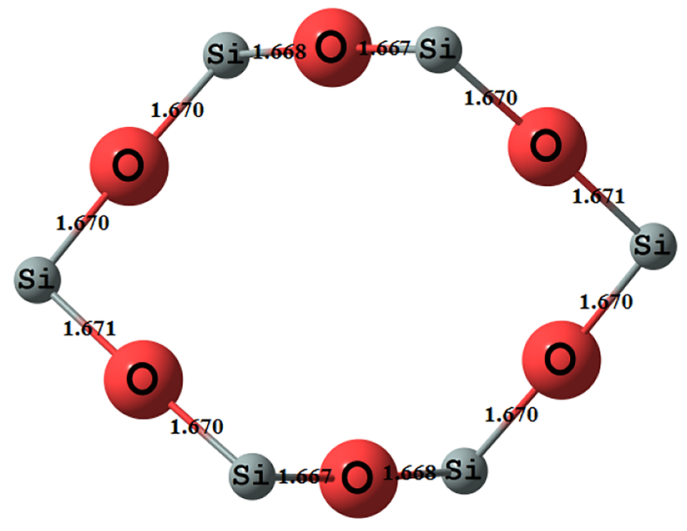

$\mathrm{SiO}_{2}-\mathrm{Br}$

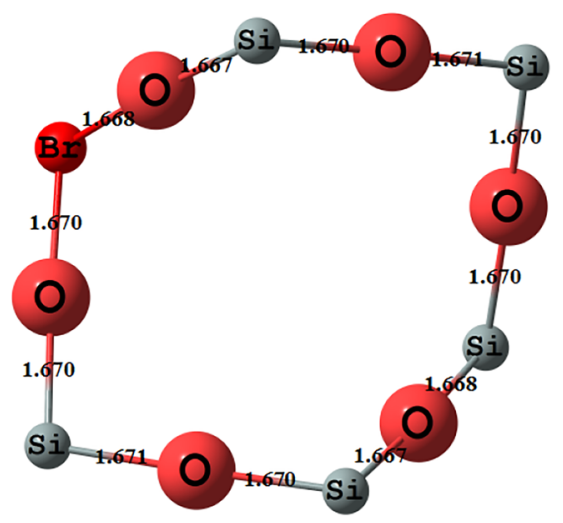

$\mathrm{SiO}_{2}$-As

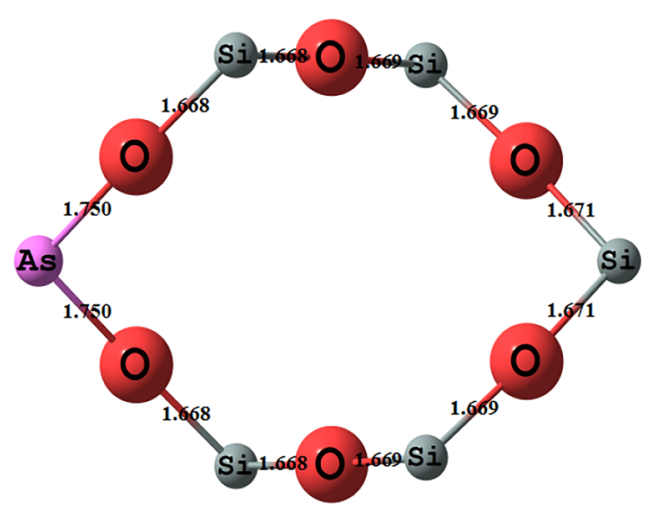

Figure 1. Bond lengths of the member ring molecule $\mathrm{SiO}_{2}$, without and with interaction of guest molecules $\mathrm{Br}$ and $\mathrm{As}$ atoms, respectively (bond length in Angstrom).
$\mathrm{SiO}_{2}$

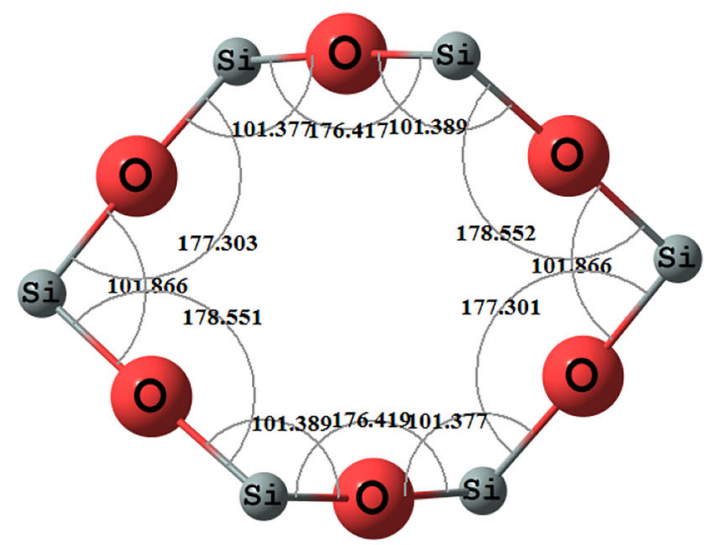

$\mathrm{SiO}_{2}-\mathrm{Br}$

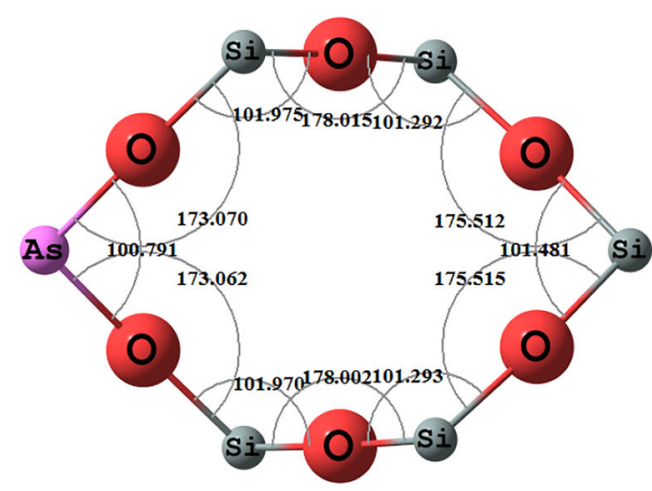

$\mathrm{SiO}_{2}$-As

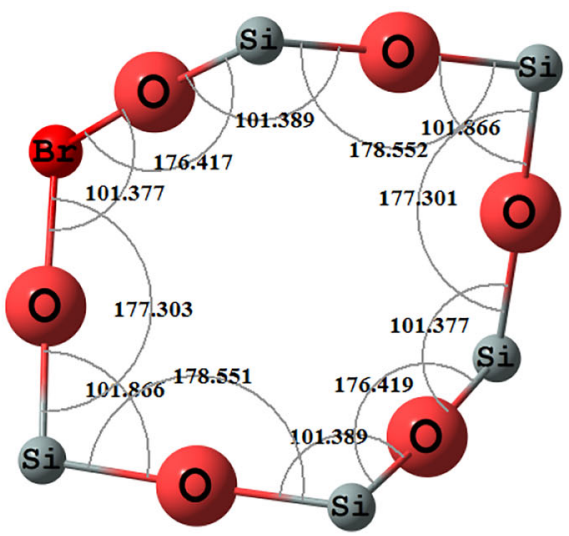

Figure 2. Bond angles of the member ring molecule $\mathrm{SiO}_{2}$, without and with interaction of guest molecules $\mathrm{Br}$ and $\mathrm{As}$ atoms, respectively (bond angles in degrees). 
Table 1. Structural factors for the silica single-wall nanotubes (experimental data [54,55]) and the calculated unit cell ring SiNTs.

\begin{tabular}{lccc}
\hline Parameter & HF/6-311G & Experimental & $\begin{array}{c}\text { Previously } \\
\text { calculated }\end{array}$ \\
\hline $\mathrm{Si}-\mathrm{O}(1)(\AA)$ & $1.670-1.671$ & $1.6034^{\mathrm{a}}$ & $1.6056^{\mathrm{a}}$ \\
$\mathrm{Si}-\mathrm{O}(2)(\AA)$ & $1.667-1.668$ & $1.6026^{\mathrm{a}}$ & $1.6062^{\mathrm{a}}$ \\
$\mathrm{Si}-\mathrm{O}-\mathrm{Si}($ deg.) & $176.417-178.552$ & $146.5^{\mathrm{a}}$ & $145.8^{\mathrm{a}}$ \\
$\mathrm{O}-\mathrm{Si}-\mathrm{O}($ deg.) & $101.377-101.866$ & $109.4^{\mathrm{b}}$ & $100.84^{\mathrm{b}}$ \\
\hline
\end{tabular}

${ }^{\mathrm{a}}$ Reference [54].

${ }^{\mathrm{b}}$ Reference [55].

and softness $(S)$ as

$$
S=1 / \eta, \quad S=-2 /\left(E_{\mathrm{HOMO}}-E_{\mathrm{LUMO}}\right) .
$$

Chemical substance hardness simply is the level of resistance to the distortion or polarization of the substances under a small disorder of chemical reaction; more the hardness more the sizable energy gap molecule [47].

\section{Results and discussion}

The minimum energy structures for doped SiNTs by replacing silicon with $\mathrm{Br}$ and $\mathrm{As}$ are presented in figures 1 and 2.
From these figures and table 1, it can be seen that $\mathrm{Si}-\mathrm{O}$ the bond lengths and $\angle \mathrm{O}-\mathrm{Si}-\mathrm{O}$ or $\angle \mathrm{Si}-\mathrm{O}-\mathrm{Si}$ bond angles of the studied nanotube rings using the model are close to those of experimental and previous calculation measurements.

It is clear that the geometric structures of Br- and As-doped SiNTs do not present dramatic changes compared with pure silica. To clearly show the guest molecule positions relative to pure $\mathrm{SiO}_{2}$ rings, the cross-view is depicted in both figures 1 and 2.

Energy gap $=$ the lowest unoccupied molecular orbital - the highest occupied molecular orbital $(\mathrm{DE}=\mathrm{LUMO}$ - HOMO), in electron volts. The energy gap is an indication of the stability of molecules [50,51]. A small energy gap indicates low stability, because it is energetically acceptable to add electrons to the LUMO and to accept electrons from the HOMO [50-52]. The energy levels of $\mathrm{SiO}_{2}$ and $\mathrm{SiO}_{2}$ doped with $\mathrm{Br}$ and $\mathrm{As}$ are presented in figure 3, respectively.

The molecular orbital density plots for $\mathrm{SiO}_{2}$ and $\mathrm{SiO}_{2}$ doped with $\mathrm{Br}$ and $\mathrm{As}$, respectively, are shown in figure 4. The frontier orbitals of the member ring molecule $\mathrm{SiO}_{2}$ are relatively delocalized and spread above the complete surface of molecules. However, the frontier orbitals of the doped molecules become localized clearly because of the incidence of dopant atoms.

HOMO, LUMO, the energy gap DE, hardness and softness are illustrated in table 2 .
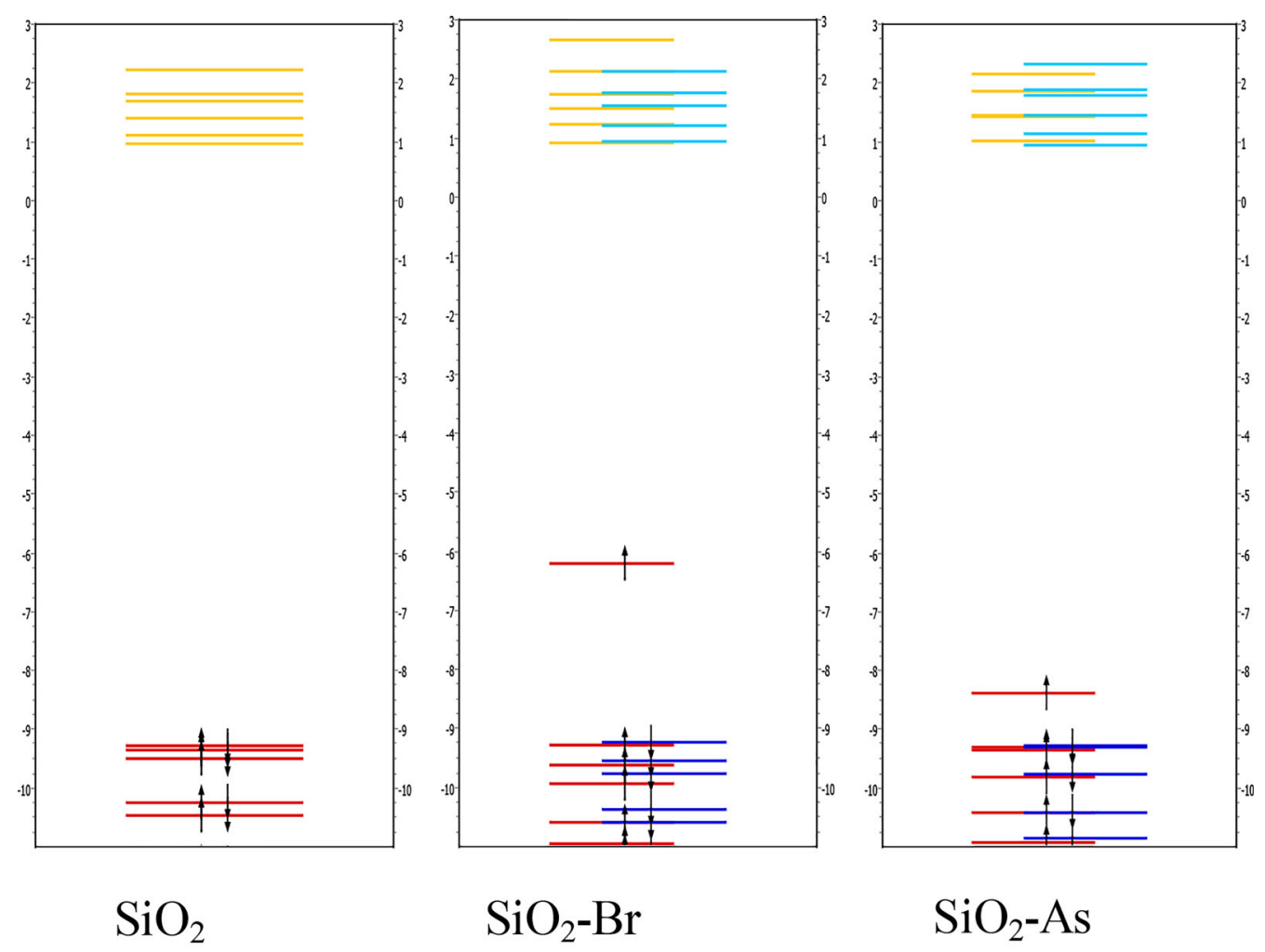

Figure 3. Energy level diagrams for $\mathrm{SiO}_{2}$ and $\mathrm{SiO}_{2}$ doped with $\mathrm{Br}$ and $\mathrm{As}$, respectively. 
$\mathrm{SiO}_{2}$

$\mathrm{HOMO}=-9.28731908 \mathrm{ev}$

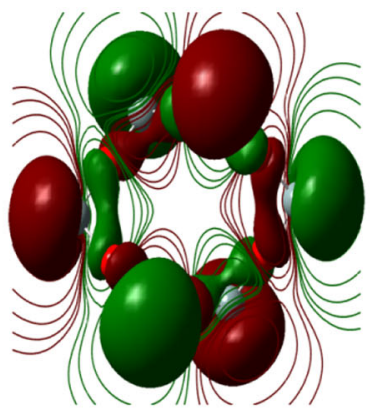

$\mathrm{EG}=10.253602996 \mathrm{ev}$

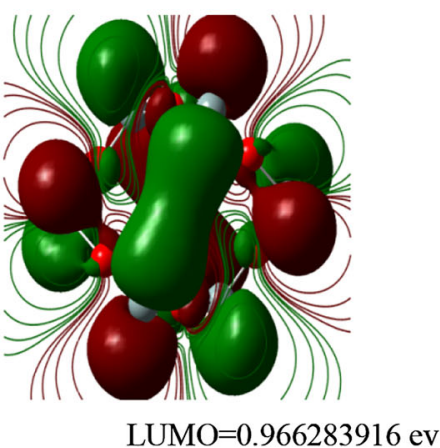

$\mathrm{SiO}_{2}-\mathrm{Br}$

$\mathrm{HOMO}=-6.207510192 \mathrm{ev}$

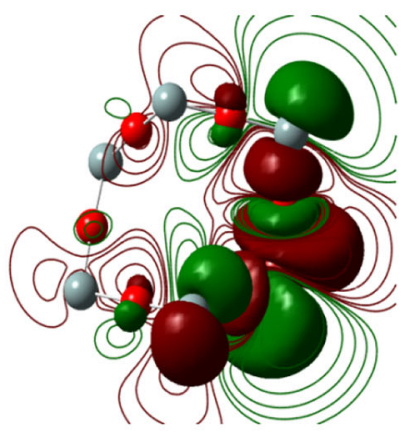

$\mathrm{EG}=7.121547836 \mathrm{ev}$

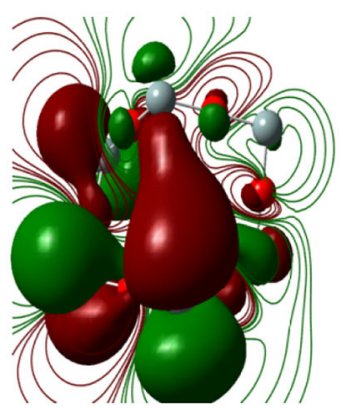

LUMO $=0.914037644 \mathrm{ev}$
$\mathrm{SiO}_{2}-\mathrm{As}$

$\mathrm{HOMO}=-8.390424744 \mathrm{ev}$

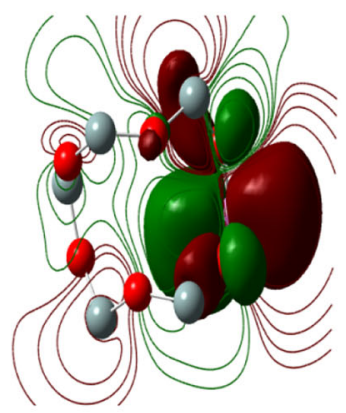

$\mathrm{EG}=9.326231668 \mathrm{ev}$

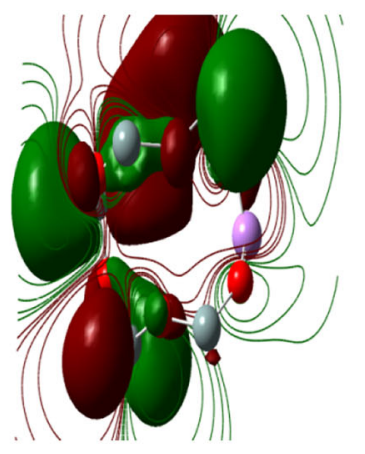

LUMO $=0.935806924 \mathrm{ev}$

Figure 4. $\mathrm{HOMO}, \mathrm{LUMO}$ and $\mathrm{DE}$ for $\mathrm{SiO}_{2}$ and $\mathrm{SiO}_{2}$ doped with $\mathrm{Br}$ and $\mathrm{As}$, respectively.

Table 2. Calculations of HOMO, LUMO, DE, $\eta$ and $S$ for $\mathrm{SiO}_{2}$ and $\mathrm{SiO}_{2}$ doped with $\mathrm{Br}$ and $\mathrm{As}$, respectively.

\begin{tabular}{lccrcl}
\hline Molecule & $E_{\text {LUMO }}$ & $E_{\text {HOMO }}$ & DE & $\eta$ & \multicolumn{1}{c}{$S$} \\
\hline $\mathrm{SiO}_{2}$ & 0.966 & -9.287 & 10.254 & 5.127 & 0.195 \\
$\mathrm{SiO}_{2} / \mathrm{Br}$ & 0.914 & -6.208 & 7.122 & 3.561 & 0.2801 \\
$\mathrm{SiO}_{2} / \mathrm{As}$ & 0.936 & -8.390 & 9.326 & 4.663 & 0.215 \\
\hline
\end{tabular}

For these calculations from table 1 and as shown in figures 3 and 4, we observed that the substitution of $\mathrm{Br}$ and As atoms on silica single-wall nanotubes affects the HOMO and LUMO. The calculated energy gaps of all these silica doped with $\mathrm{Br}$ and As clusters are reduced compared with the energy gap of pure silica. This means that in any excitation process silica doped with $\mathrm{Br}$ and As molecules needs more energy than that of pure silica. It suggests that electrons in all silica doped with $\mathrm{Br}$ and As molecules are easier to excite from the HOMO to LUMO levels than in pure silica. One might particularly assume to have a broad selection of new semiconductors because a number of spaces are formed with regard to the substituents and the range of substitution.

In summary, the stability for each group is decreased by substitution with $\mathrm{Br}$ and As atoms. Table 2 shows the same behaviour with respect to hardness and the opposite behaviour for softness.

\section{Conclusion}

The structure, energy band gaps and mechanical properties were computed for SiNTs, in addition to some of their derivatives that doped with $\mathrm{Br}$ and As elements by executing the HF method/6-311G level. We have seen that all obtained results with respect to the geometric structures of pure SiNTs are in good agreement with the related experiment and no change in the computed bond lengths and bond angles of doped silica. The $\mathrm{As}$ and $\mathrm{Br}$ atoms led to a decrease in the DE of pure silica. The silica doped with $\mathrm{Br}$ and As molecules does not require more energy to be excited. 


\section{References}

[1] Cui Y and Lieber C M 2001 Science 291851

[2] Delley B and Steigmeier E F 1995 Appl. Phys. Lett. 672370

[3] Zhao Y and Yakobson B I 2003 Phys. Rev. Lett. 91035501

[4] Leu P W, Shan B and Cho K 2006 Phys. Rev. B 73195320

[5] Vo T, Williamson A J and Galli G 2006 Phys. Rev. B 74045116

[6] Singh A K, Kumar V, Note R and Kawazoe Y 2006 Nano Lett. 6920

[7] Rurali R, Aradi B, Frauenheim T and Gali A 2007 Phys. Rev. B 76113303

[8] Cui Y, Zhong Z, Wang D, Wang W U and Lieber C M 2003 Nano Lett. 3149

[9] Duan X, Huang Y, Cui Y, Wang J and Lieber C M 2001 Nature 40966

[10] Huang Y, Duan X, Cui Y, Lauhon L J, Kim K H and Lieber C M 2001 Science 2941313

[11] Tans S J, Verschueren A R M and Dekker C 1998 Nature 393 49

[12] Martel R, Schmidt T, Shea H R, Hertel T and Avouris P 1998 Appl. Phys. Lett. 732447

[13] Wind S J, Appenzeller J, Martel R, Derycke V and Avouris P 2002 Appl. Phys. Lett. 803817

[14] Derycke V, Martel R, Appenzeller J and Avouris P 2001 Nano Lett. 1453

[15] Martel R, Derycke V, Lavoie C, Appenzeller J, Chan K K, Tersoff J et al 2001 Phys. Rev. Lett. 87256805

[16] Cui Y Q, Wei H, Park H K and Lieber C M 2001 Science 293 17

[17] Hahm J and Lieber C M 2003 Nano Lett. 451

[18] Gao Z, Agarwal A, Trigg A D, Singh N, Fang C, Tung C-H et al 2007 Anal. Chem. 793291

[19] Patolsky F, Zheng G and Lieber C M 2006 Nat. Protoc. 11711

[20] Cheng M M-C, Cuda G, Bunimovich Y L, Gaspari M, Heath J R, Hill H D et al 2006 Curr. Opin. Chem. Biol. 1011

[21] Kuang Q, Lao C, Wang Z L, Xie Z and Zheng L 2007 J. Am. Chem. Soc. 1296070

[22] Li Y, Qian F, Xiang J and Lieber C M 2006 Mater. Today 918

[23] Star A, Lu Y, Bradley K and Grüner G 2004 Nano Lett. 41587

[24] Zhong Z, Qian F, Wang D and Lieber C M 2003 Nano Lett. 3 343

[25] Wong H 2002 Microelectron. Reliab. 42317

[26] Read A J, Needs R J, Nash K J, Canham L T, Calcott P D J and Qteish A 1992 Phys. Rev. Lett. 691232

[27] Ohno T, Shiraishi K and Ogawa T 1992 Phys. Rev. Lett. 69 2400

[28] Hybertsen M S and Needels M 1993 Phys. Rev. B 484608
[29] Aradi B, Ramos L E, Deák P, Köhler T, Bechstedt F, Zhang R Q et al 2007 Phys. Rev. B 7635305

[30] Singh A K, Kumar V, Note R and Kawazoe Y 2005 Nano Lett. 52302

[31] Rurali R and Lorente N 2005 Phys. Rev. Lett. 94026805

[32] Zhao X M, Wei C, Yang L and Chou M Y 2004 Phys. Rev. Lett. 9223

[33] Scheel H, Reich S and Thomsen C 2005 Phys. Status Solidi (b) $\mathbf{2 4 2} 2474$

[34] Zhang R Q, Lifshitz Y, Ma D D D, Zhao Y L, Frauenheim T, Lee S T et al 2005 J. Chem. Phys. 123144703

[35] Ng M-F, Zhou L, Yang S-W, Sim L Y, Tan V B C and Wu P 2007 Phys. Rev. B 76155435

[36] Nolan M, O'Callaghan S, Fagas G, Greer J C and Frauenheim T 2006 Nano Lett. 734

[37] Delerue C, Allan G and Lannoo M 1993 Phys. Rev. B 4811024

[38] Fagan B, Baierle R J, Mota R, Silva J R and Fazzio A 1994 Phys. Rev. B 619994

[39] Yang X and Ni J 2005 Phys. Rev. B 72195426

[40] Barnard A S and Russo S P 2003 J. Phys. Chem. 1077577

[41] Zhang R Q, Lee H-L, Li W-K and Teo B K 2005 J. Phys. Chem. 1098605

[42] Zhang M, Kan Y H, Zang Q J, Su Z M and Wang R S 2003 Chem. Phys. Lett. 37981

[43] Seifert G, Kohler T, Urbassek H M, Hernandez E and Frauenheim T 2001 Phys. Rev. B 63193409

[44] Pour N, Altus E, Basch H and Hoz S 2010 J. Phys. Chem. C 114 10386

[45] Pour N, Altus E, Basch H and Hoz S 2009 J. Phys. Chem. C 113 3467

[46] Bai J, Zeng X C, Tanaka H and Zeng J Y 2004 Proc. Natl. Acad. Sci. 1012665

[47] Wang H, Wang X, Wang H, Wang L and Liu A 2007 J. Mol. Model 131147

[48] Sastri V S and Perumareddi J R 1997 Corrosion 53617

[49] Frisch M J, Trucks G W, Schlegel H B, Scuseria G E, Robb M A, Cheeseman J R et al 2004 Gaussian 03 (Revision D 01) Gaussian Inc., Wallingford, CT

[50] Diener M D and Alford J M 1998 Nature 393668

[51] Moran D, Stahl F, Bettinger H F, Schaefer III H F and Schleyer P V R 2003 J. Am. Chem. Soc. 1256746

[52] Yang S H, Pettiette C L, Conceicao J, Cheshnovsky O and Smalley R E 1987 Chem. Phys. Lett. 139233

[53] Handschuh H, Ganteför G, Kessler B, Bechthold P S and Eberhardt W 1995 Phys. Rev. Lett. 741095

[54] Zele Y M et al 2012 New J. Phys. 14113029

[55] Zhang S-L et al 2010 Chin. J. Chem. Phys. 23497 